BANCA D'ITALIA

E U R O S I S T E M A

Questioni di Economia e Finanza

(Occasional Papers)

Is deflation good or bad? Just mind the inflation gap

by Marco Casiraghi and Giuseppe Ferrero 

13 BANCA D'ITALIA

E U ROS I S T E M A

\section{Questioni di Economia e Finanza}

(Occasional papers)

Is deflation good or bad? Just mind the inflation gap

by Marco Casiraghi and Giuseppe Ferrero

Number 268 - April 2015 
The series Occasional Papers presents studies and documents on issues pertaining to the institutional tasks of the Bank of Italy and the Eurosystem. The Occasional Papers appear alongside the Working Papers series which are specifically aimed at providing original contributions to economic research.

The Occasional Papers include studies conducted within the Bank of Italy, sometimes in cooperation with the Eurosystem or other institutions. The views expressed in the studies are those of the authors and do not involve the responsibility of the institutions to which they belong.

The series is available online at www.bancaditalia.it.

ISSN $1972-6627$ (print)

ISSN 1972-6643 (online)

Printed by the Printing and Publishing Division of the Bank of Italy 


\title{
IS DEFLATION GOOD OR BAD? JUST MIND THE INFLATION GAP
}

\author{
by Marco Casiraghi* and Giuseppe Ferrero*
}

\begin{abstract}
We explain why the macroeconomic effects of shocks to inflation of the same size but opposite sign are not necessarily symmetric. All in all, the costs of deflation and disinflation tend to exceed those of inflation owing to the presence of constraints in the economy, namely the zero lower bound on nominal interest rates, borrowing limits, and downward nominal wage rigidity. When these constraints are binding, they can prevent monetary policy from closing the inflation gap, agents from deleveraging, and the labor market from clearing. The impact of a disinflationary shock on the tightness of these constraints depends on the cyclical and structural conditions of the economy. We also argue that it would be a mistake to assume that perverse effects can arise only when prices decrease, and that the classification of deflationary episodes into good (supply driven) and bad (demand driven) is not only incorrect, it is also misleading in terms of policy implications.
\end{abstract}

JEL Classification: E31, E52, E58.

Keywords: deflation, zero lower bound, downward wage rigidity, borrowing constraints.

\section{Contents}

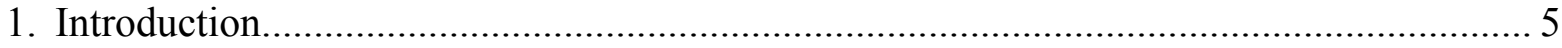

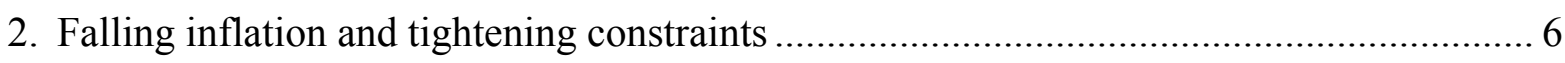

2.1 The zero lower bound on nominal interest rates .............................................. 6

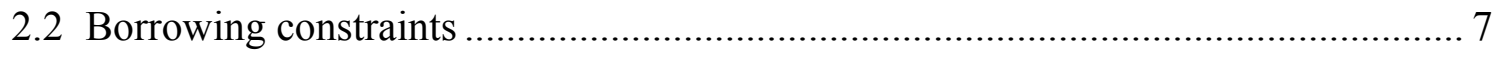

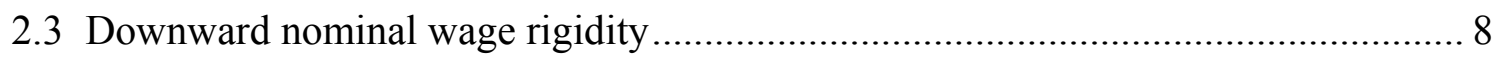

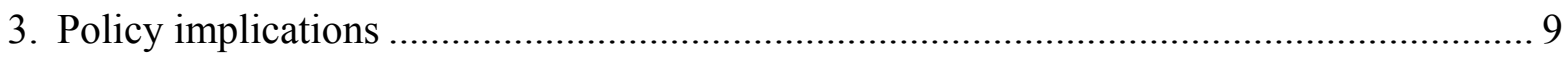

4. Current macroeconomic conditions and constraints' tightness in the euro area .............. 10

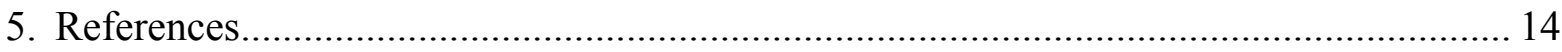

* Bank of Italy, Directorate General for Economics, Statistics and Research. The usual disclaimer applies. 



\section{Introduction}

Most modern central banks pursue the objective of price stability by adopting an inflation target. Although the presence of nominal rigidities implies that price changes reduce social welfare, central banks' target for the inflation rate is not zero, but is typically slightly positive. The reason is that the macroeconomic effects of shocks to inflation of the same size but opposite sign are not necessarily symmetric.

The aim of this work is to provide an answer to the following questions. Why are the economic consequences of deflation and low inflation worse than those associated with high inflation? How do the characteristics of the economy affect the costs of negative shock to the inflation rate? What are the policy implications, in particular for the euro area in the current circumstances?

The main conclusions are summarized below.

- The costs of deflation and disinflation tend to exceed those of inflation due to the presence of constraints in the economy, namely the zero lower bound on nominal interest rates, borrowing limits, and downward nominal wage rigidity (though in the last case the short term effects on inflation are not clear cut, as we clarify below).

- The impact of a negative shock to inflation on the tightness of these constraints depends on the cyclical conditions and the structural characteristics of the economy. The level of public and private debt and the inflation expectation formation process play a key role.

- When the above constraints are binding, they can prevent monetary policy from closing the inflation gap, agents from deleveraging, and the labor market from clearing. Moreover, a debt-deflation spiral and a disanchoring of inflation expectations may occur.

- The classification of deflationary episodes into good (supply driven) and bad ones (demand driven) appears to be incorrect and misleading in terms of the policy implications. As long as a shock makes the above constraints binding, it does not matter whether deflation arises because of demand or supply factors; in both cases the effectiveness of monetary policy and the self-rebalancing of the economy are hampered.

- It would be a mistake to assume that perverse effects can arise only if the price level falls, since the constraints become tighter gradually as inflation declines, even when it remains positive.

- Another mistake would be for the central bank not to intervene before a disanchoring of long-term expectations occurs. The consequent decline in long-term nominal rates would leave monetary policy with little room to reduce long-term real rates through nonstandard measures.

- Empirical evidence for the euro area suggests that the three constraints discussed above have become increasingly tight in recent months, prompting strong monetary policy reactions by the ECB aimed at bringing inflation back to target. 


\section{Falling inflation and tightening constraints}

In order to minimize social welfare costs, central banks need to maintain the difference between inflation and its target (i.e. the inflation gap) as close as possible to zero (Woodford, 2003). Typically, the target is slightly positive because positive and negative shocks to inflation that are equal in terms of absolute deviation from the target may imply very different welfare costs.

The reason for this asymmetry is the presence of constraints on the decisions of economic agents (households, firms and policy-makers) that become tighter when the price level decreases (deflation) or inflation declines while remaining positive (disinflation). When binding, these constraints can hinder or even prevent policy-makers from being able to close the inflation gap, keeping markets from clearing. The impact of a negative shock to inflation on the tightness of these constraints depends on the state of the business cycle and on the structural characteristics of the economy.

Several contributions to the current debate on deflationary risks distinguish between episodes of deflation according to the type of shock that caused them: a supply shock produces good deflation, while a demand shock leads to bad deflation. ${ }^{1}$ This approach misleading because it suggests that good deflation yields higher output growth and bad deflation causes a recession, whereas macroeconomic effects depend on how shocks to inflation affect the tightness of the constraints. From this viewpoint, the nature of the shocks is largely irrelevant, since the negative consequences of deflation derive from limits to the response of policy authorities and to the selfadjustment of the economy.

The remainder of this section briefly describes the relevant constraints, discusses the factors that affect their tightness and explains the consequences they have on the economy when they become binding.

\subsection{The zero lower bound on nominal interest rates}

When shocks push inflation below target, central banks respond by reducing official rates. Through the transmission mechanism, the other nominal interest rates in the economy also decline. In the presence of price rigidities, this implies lower real interest rates, which in turn positively affect aggregate demand and ultimately prices, thus closing the inflation gap. However, the possibility to hold currency, whose nominal return is zero, prevents any nominal interest rate from going negative (except for small deviations made possible by the cost of storing bills).

\subsubsection{Factors affecting its tightness}

Among the factors that affect the probability that nominal rates reach the zero lower bound (ZLB), one of the most relevant is the phase of the business cycle when the negative shock hits the economy. When the cycle is close to its peak and the output gap is positive, short-term nominal interest rates are relatively high and conventional monetary policy has more room to maneuver. Conversely, when the cycle is in a trough, the probability of hitting the ZLB is higher.

\footnotetext{
${ }^{1}$ See Borio and Filardo (2004), “Back to the future? Assessing the deflation record”, BIS Working paper, No. 152.
} 
Another factor is the impairment of the transmission mechanism of monetary policy. When transmission is impaired, the central bank must respond more aggressively to achieve the same goals in the economy, thus increasing the likelihood of hitting the ZLB.

\subsubsection{Consequences when it binds}

The existence of the ZLB limits the effectiveness of conventional monetary policy, as the central bank cannot reduce real interest rates when the constraint is binding. In this situation, real rates simply move one-for-one (but in the opposite direction) with changes in expected inflation. Therefore, while central banks can always offset inflationary shocks, given that nominal interest rates do not have an upper bound, they cannot counteract disinflationary or deflationary pressures by adjusting the policy rate, one the economy is at the ZLB.

A binding ZLB also increases the risk of a disanchoring of long-term expectations, which would further raise real rates. Fully rational agents anticipate that the ZLB may prevent the central bank from closing the inflation gap. The risk of a disanchoring is even higher if agents use past forecast errors and current values to update their inflation expectations. The probability that inflation expectations become de-anchored when inflation remains below target for a prolonged period of time is larger with learning than with fully informed and perfectly rational agents. ${ }^{2}$

\subsection{Borrowing constraints}

Similar to the constraint considered above, real wealth cannot decrease below a certain level (i.e. real debt has an upper bound). In other words, agents face borrowing constraints since the amount they may be able to borrow depends on their expected future income and the value of the collateral they own due to the presence of financial frictions and market imperfections.

\subsubsection{Factors affecting their tightness}

As long as debt obligations are fixed in nominal terms, any inflation surprise changes the real burden of debt and affects the tightness of agents' borrowing constraints. When inflation falls below the level expected when debt was contracted, the real value of debt increases and its service cost may rise as well, unless a reduction of nominal rates prevents real rates from rising. ${ }^{3}$ The impact of falling inflation is larger if agents are highly leveraged and thus closer to hitting their borrowing constraints. Moreover, borrowing constraints are more likely to tighten following a sharp decline in the price of assets that are typically used as collateral (e.g. housing or government bonds).

Banks' behavior, itself affected by cyclical conditions, may result in a further tightening of borrowing constraints. Credit rationing, in particular, may arise if the health of the banking system deteriorates to the point that intermediaries start deleveraging in order to meet regulatory requirements in terms of capital and liquidity. For instance, when a bubble bursts or the economic outlook remains weak for a prolonged period of time, banks may incur significant losses, which in turn induce them to deleverage, as the origination of new loans would be too costly in terms of capital consumption.

\footnotetext{
${ }^{2}$ See Busetti, Ferrero, Gerali and Locarno (2014), "Bounded rationality and de-anchoring of inflation expectations”, Banca d'Italia Occasional Papers, No. 252.

${ }^{3}$ If loans are fixed-rate, they are insensitive to changes in nominal interest rates.
} 


\subsubsection{Consequences when they binds}

Once borrowing constraints become binding, agents are to deleverage by increasing savings. The consequent fall in aggregate demand could reduce inflation even more, further reducing the real value of assets and raising the real burden of debt, and thus inhibiting the deleveraging process. This process is known as the "debt deflation" mechanism. ${ }^{4}$ Moreover, an unexpected fall in inflation transfers wealth from debtors to creditors via the debt deflation channel. To the extent that debtors have a higher propensity to consume than creditors, this is likely to put further downward pressure on aggregate demand. ${ }^{5}$

The implications for fiscal policy are particularly important. Like any other agent, the government may be forced to deleverage because of a binding borrowing constraint, negatively affecting aggregate demand through reductions in government spending and tax increases. In addition, discretionary fiscal interventions usually represent key policy instruments to counteract disinflationary shocks. Therefore, the need to ensure the sustainability of public debt would not only induce a fall in aggregate demand, but would also prevent fiscal policy from counteracting disinflationary pressures, leaving the central bank with the burden of closing the inflation gap.

\subsection{Downward nominal wage rigidity}

Downward nominal wage rigidity represents another constraint that introduces an asymmetry between positive and negative changes in the inflation rate. If a disinflationary shock occurs, the consequent increase in real wages cannot be offset by reductions of nominal compensation because of the workers' reluctance to accept nominal wage cuts. Therefore, the real wage will deviate from the equilibrium value that should equate demand and supply in the labor market. As we discuss below, however, the implications of this constraint are not clear cut, at least in terms of inflation in the short term, differently from the case of the two constraints considered in the previous sections. This holds, in particular, with regard to the current circumstances in the euro area.

\subsubsection{Factors affecting its tightness}

In general, the stickier are nominal wages, the higher is the risk that a negative shock to inflation tightens the constraint. Nominal wage stickiness depends on the frequency at which bargains between workers and employers occur. If these bargains take place at a low frequency, not only deflationary shocks but also unanticipated disinflationary shocks, which push the inflation rate below what was expected at the time of the last bargaining round, will raise real wages and thus increase the probability that the constraint on nominal wages becomes binding.

\subsubsection{Consequences when it binds}

The consequences of nominal wage rigidity are not obvious, if one considers the effects on both the supply and the demand side of the economy. On the one hand, it hampers the adjustment of the labor market following an unexpected fall in the inflation rate. The increase in the real wage induces firms to reduce employment in order to avoid a reduction in profits. Therefore, downward nominal wage rigidity represents a constraint to labor market clearing and impedes the self-

\footnotetext{
${ }^{4}$ See Fisher (1933), “Debt-Deflation Theory of Great Depressions”, Econometrica, Vol. 1(4), pp. 337-57.

${ }^{5}$ See Neri and Notarpietro (2014), “Inflation, debt and the zero lower bound”, Banca d'Italia Occasional Papers, No. 242.
} 
rebalancing process of the economy, which in turn makes it harder for the central bank to close the inflation gap. On the other hand, sticky wages may help stabilize output in response to temporary shocks by sustaining the real income and thus the consumption of workers in the short term. This mechanism is known as the "paradox of flexibility" ${ }^{6}$ In the aftermath of a large deleveraging shock, which puts the economy at the ZLB, the short-run aggregate demand curve is upward sloping. The reason for this seemingly perverse slope is that a lower price level increases the real interest rate, which in turn negatively affects aggregate demand. In this case, increased wage flexibility actually makes things worse, not better, because falling prices do not help sustain demand, while they intensify the debt-deflation effect by raising the real value of debt.

Assuming that the degree of downward nominal wage rigidity remains constant over time, the cons are generally considered to outweigh the pros, at least in the medium term. ${ }^{7}$ It is possible that a reduction in nominal wages leads to a fall in aggregate demand and inflation in the short run if employment does not increase fast enough to compensate for the decline in nominal compensation. However, the failure of real wages to return to their equilibrium value would eventually and inevitably cause an increase of the unemployment rate in the medium term. Should real wages or employment not decline, the profitability of firms and the return on capital would decrease, leading to a fall in investment. ${ }^{8}$ The resulting persistent output gap would contribute to hysteresis effects, raising the risk of cyclical unemployment becoming structural.

Notwithstanding, it is implausible that in a context of persistent price deflation nominal wages will not decrease. As nominal wage rigidity becomes too costly, it is likely that it will disappear. Moreover, it cannot be taken for granted that wage flexibility would help sustain inflation in the short term in a situation of very low inflation, deleveraging and weak economic activity. In particular, if agents also form their inflation expectations on the basis of the changes in nominal compensation, wages that are too flexible may amplify the impact of negative shocks to inflation, leading to deflationary spiral. Thus, the economy may be in a "lose-lose situation" such that rigid nominal wages imply higher real wages with undesirable output losses, while more flexible wages have short-term consequences that may increase deflationary risk.

\section{Policy implications}

The existence of the three constraints described above explains why the costs of deflation may exceed those of inflation. Three considerations are relevant concerning the appropriate policy responses to negative inflationary shocks.

\footnotetext{
${ }^{6}$ See Eggertsson and Krugman (2012), “Debt, Deleveraging, and the Liquidity Trap: A Fisher-Minsky-Koo Approach”, The Quarterly Journal of Economics, Vol. 127(3), pp. 1469-1513.

${ }^{7}$ Some empirical evidence available for the euro area supports this view, as highlighted by President Draghi, who argued that the economies that have performed better during the crisis in terms of employment also are those in which the labor market was more flexible and thus capable to adjust to economic conditions (see the speech "Unemployment in the euro area”, Jackson Hole, 22 August 2014).

${ }^{8}$ As explained by Peter Praet: "Deflation means that prices in the economy as a whole are falling steadily. In such a situation, workers' wages are too high in comparison with the overall price level, and collective wage agreements cannot simply be changed. Therefore, production becomes too expensive and businesses stop investing because they assume that demand is falling. It is a vicious circle that leads to sharply declining economic activity and rising unemployment - the Great Depression in the United States in the 1930s has taught us that.” (see interview with Süddeutsche Zeitung, 31 January 2015).
} 
First, it is not the nature of the negative shock to inflation that determines whether it is good or bad. According to a common taxonomy, deflation is good or bad if it is caused by a supply or a demand shock respectively, but this classification does not consider that the presence of constraints may prevent the economy from responding effectively to the shock. Consider the case of a positive supply shock that increases potential output. If the ZLB and the borrowing constraints bind, output will not increase enough to close the output gap, which in turn will induce a fall in inflation. The resulting increase in the real rate will depress aggregate demand and widen the output gap even further. In other words, when the borrowing constraints bind, the economy can neither counteract negative shocks nor benefit from positive ones.

Second, although such constraints are more likely to be binding when the price level decreases, not all deflationary shocks will cause them to bind, while any fall in the inflation rate may increase their tightness. Therefore, it would be a mistake to draw a line at zero and assume that perverse effects can arise only if the price level decreases. Rather, negative effects are not only triggered by outright deflation, but also by inflation running below expectations. For instance, the incentive to postpone consumption becomes gradually stronger as the real rate increases and does not suddenly materialize when the price level begins to decrease.

Third, the existence of the constraints means not only that the sign of the response of the central bank depends on the sign of the shock to inflation, but also that the aggressiveness and timeliness of the response may need to be different. More specifically, the central bank would be mistaken to wait for the constraints to become binding before intervening in the wake of a negative inflation shock. For example, when inflation falls to very low levels and short-term rates are at their lower bound, medium and long-term nominal yields play a primary role in stimulating the economy since the central bank can try to decrease the corresponding real rates through unconventional monetary policies. A disanchoring of inflation expectations would, however, result in declining long-term nominal yields, weakening the effectiveness of such policies by reducing the scope for lowering their real component. Moreover, the impact would be even smaller if agents were highly leveraged and thus limited in their capacity to borrow. Therefore, the central bank must intervene before medium- and long-term nominal yields become too low.

\section{Current macroeconomic conditions and constraints' tightness in the euro area}

In the last two years, the euro area has experienced a rapid and sizeable decline of the inflation rate in both core and peripheral countries, which has even turned negative in some member states (Figure 1, panel A). The risk of a prolonged period of excessively low inflation has increased significantly since the fall of 2013, when a sequence of negative surprises to inflation caused a sharp downward revision of inflation expectations at all horizons (Figure 1, panel B).

These negative surprises have increased the risk of disanchoring of long-term expectations. Busetti et al. (2014) show that, under the assumption that agents have incomplete knowledge and bounded rationality, a sequence of disinflationary shocks such as those that hit the euro area in the second half of 2013 and beginning of 2014 may reduce inflation expectations by up to 1 percentage point with respect to the assumption of fully informed and perfectly rational agents. 


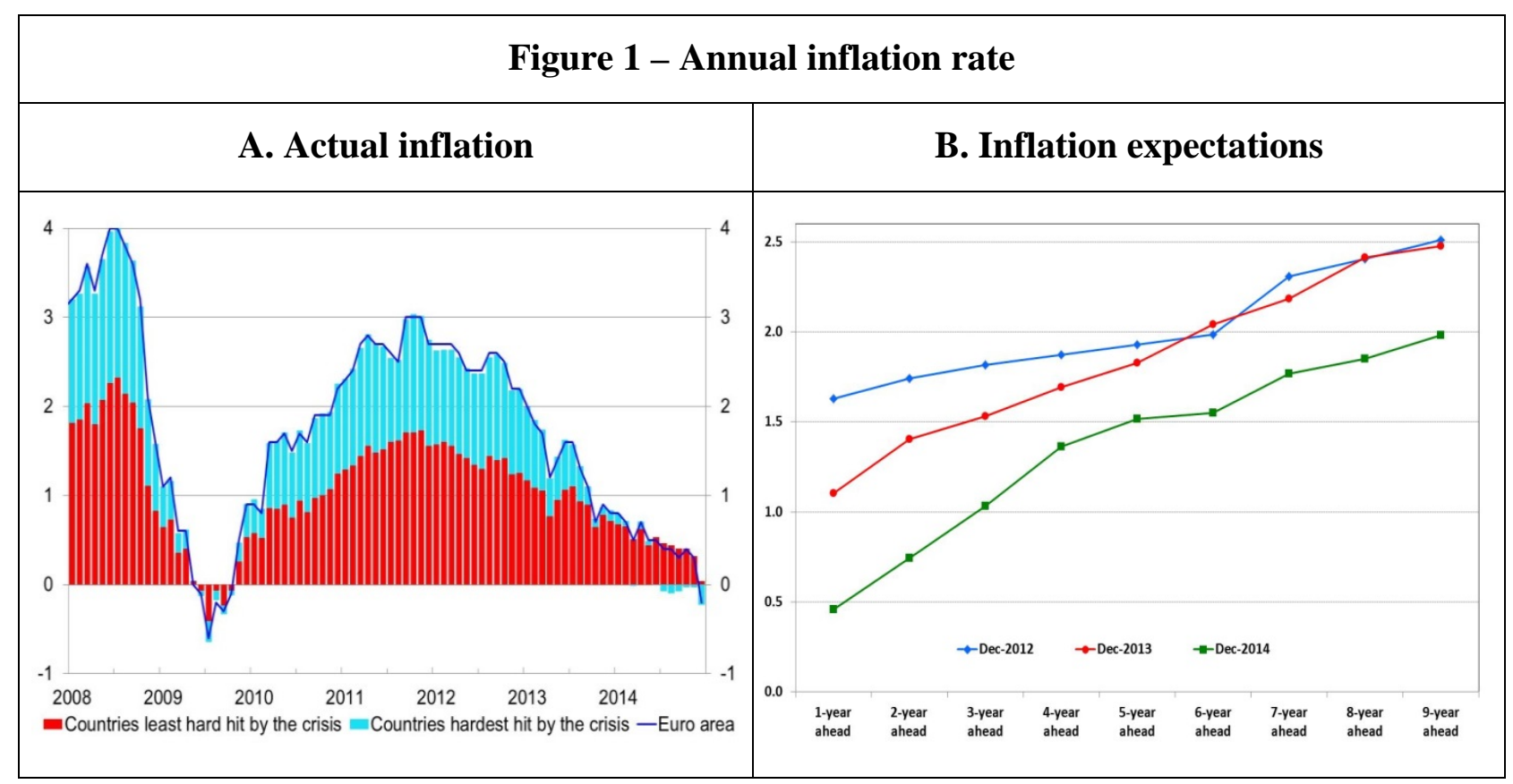

Note: (1) Actual inflation is the percentage change of the HICP index. (2) Inflation expectations are based on inflation swaps.

In order to assess how the euro area economy is likely to be affected by the fall in actual and expected inflation, it is necessary to understand whether the ZLB, borrowing constraints and downward nominal wage rigidity are already binding or are close to becoming so.

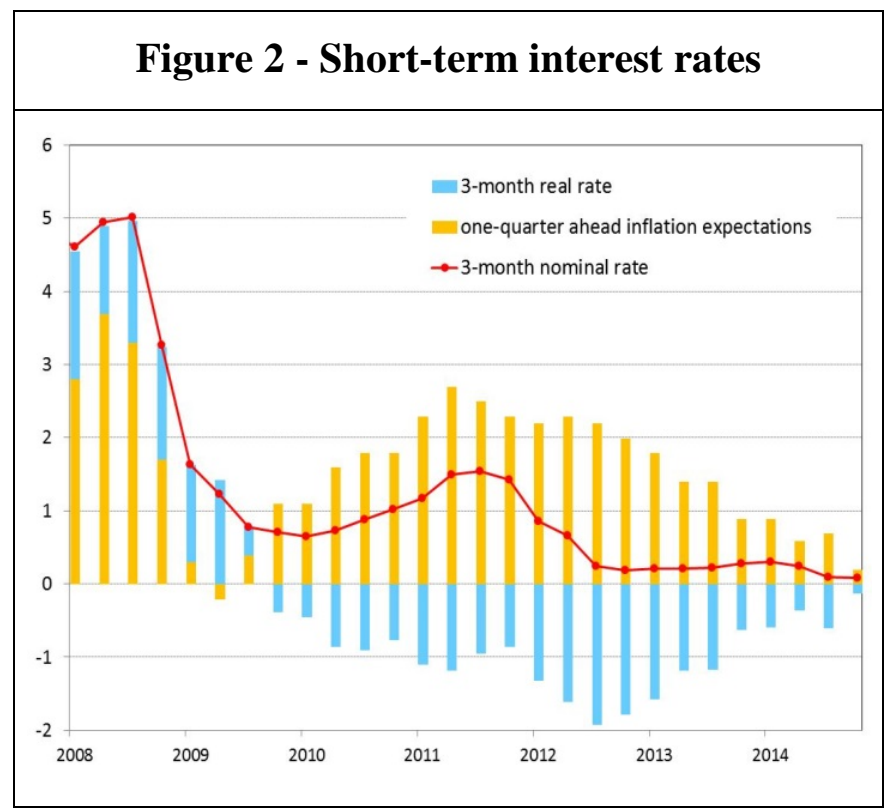

Note: (1) 3-month Euribor computed as average of daily data in last month of the quarter. (2) The real rate is the difference between the Euribor and inflation expectations for the next quarter of the professional analysts surveyed by Consensus Economics. 
Today, short-term nominal rates are at the ZLB and, as a consequence, short-term real rates have been increasing due to the fall in inflation expectations, which implies monetary tightening instead of the necessary accommodation (Figure 2).

From a historical perspective, the level of both public and private debt suggests that leverage is still very high (Figure 3, panel A), meaning that borrowing constraints may be binding. Moreover, according to the Bank Lending Survey (BLS) of the Eurosystem, banks have tightened the conditions of credit supply to the private sector (Figure 3, panel B), which in turn imply tighter borrowing constraints. Consequently, the risk that a disinflationary or deflationary shock will make borrowing constraints binding, forcing firms and households to deleverage and governments to reduce their budget deficits to ensure the sustainability of public debt, is very high.

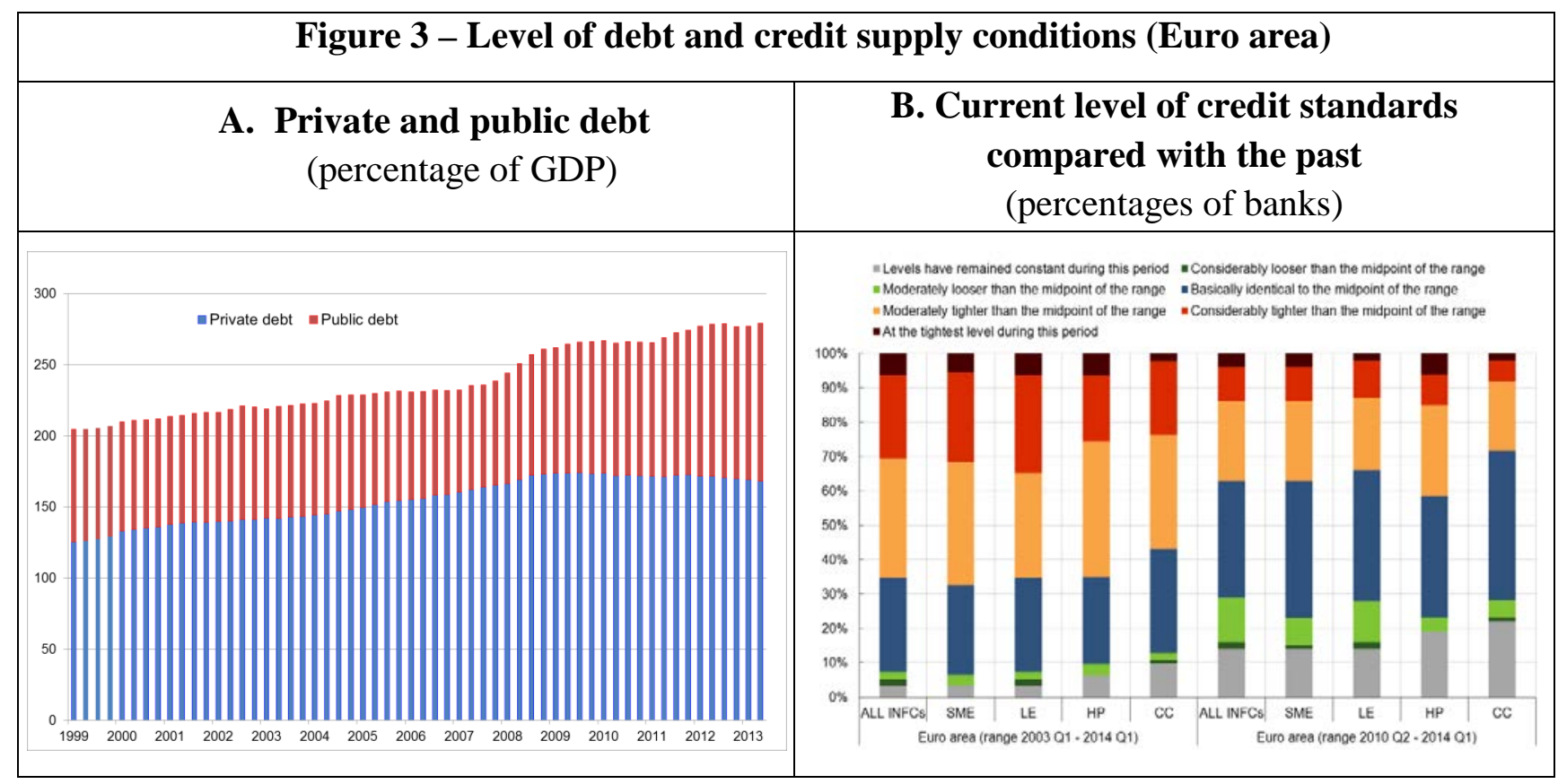

Note. (i) Private debt: reporting institutional sector non-financial private sectors, ratio of debt to gross domestic product at market prices, non-consolidated, percentage. (ii) Public debt: general government consolidated gross debt, percentage of GDP at market prices. (iii) The April 2014 BLS survey questionnaire included, for the first time, a question on the current level of credit standards as compared with the levels that have prevailed between the first quarter of 2003 and now, as well as between the second quarter of 2010. (iv) "All NFCs" indicates loans to all non-financial corporations, "SME” indicates loans to small and medium-sized enterprises, "LE” indicates loans to large enterprises, "HP” indicates loans to households for house purchase, and “CC” indicates consumer credit and other lending to households.

The adjustment via nominal wage reductions has been very limited, despite unprecedented high unemployment rates (Figure 4, panel A). Only Greece and Ireland have experienced a significant decrease in overall nominal compensation since 2008 (Figure 4, panel B). Wage flexibility in Ireland could help explain the different unemployment dynamics compared to other countries, like Spain, where the labor market adjustment could not take place through nominal compensation and thus occurred primarily through a fall in the number of employees. 


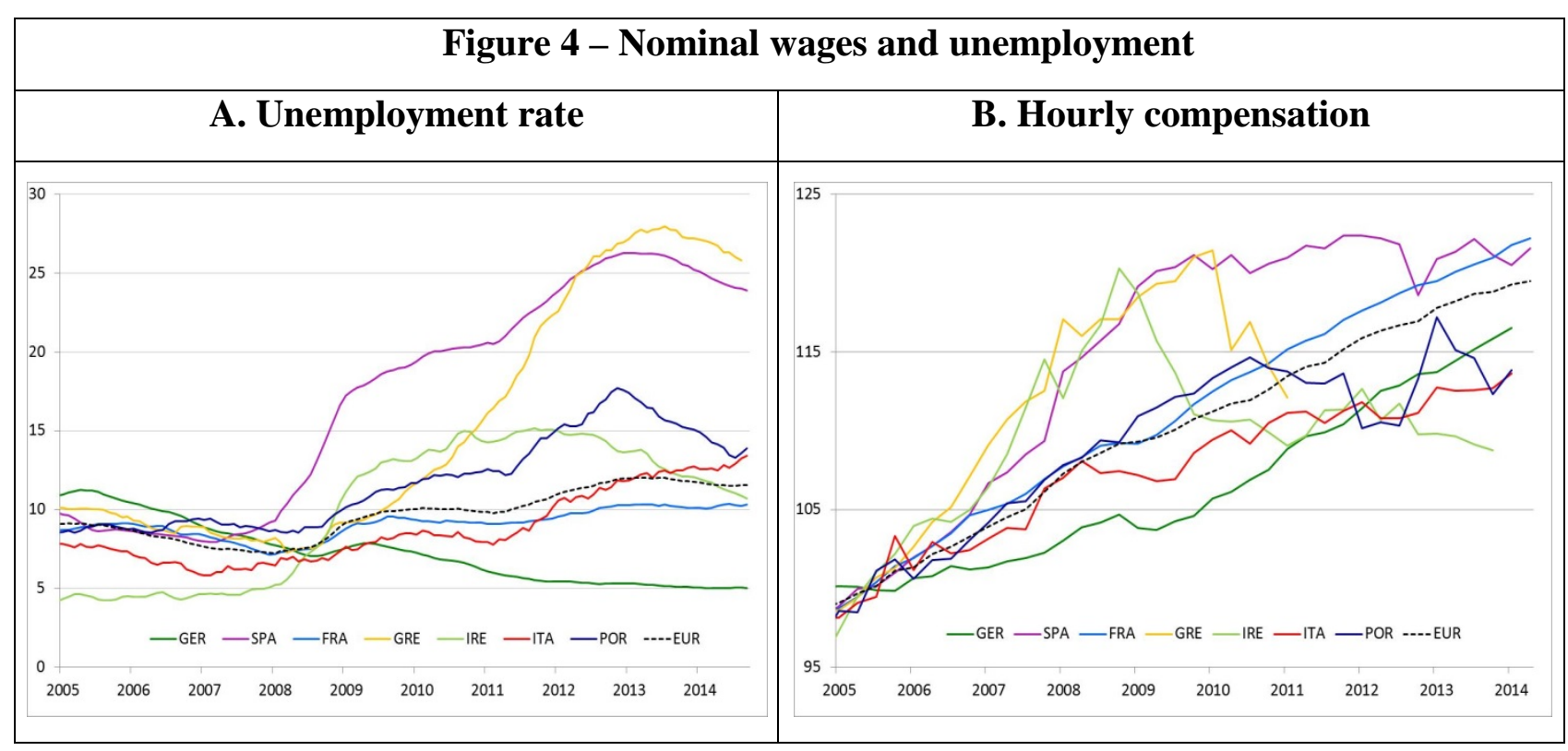

Note: (1) Hourly compensation is compensation per employee, current prices, seasonally adjusted, not working day adjusted, index. (2) Unemployment rate is standardized unemployment as percentage of civilians, seasonally adjusted, not working day adjusted. 


\section{References}

Borio, C. and A. Filardo (2004), "Back to the future? Assessing the deflation record”, BIS Working paper, No. 152.

Busetti, F., Ferrero G., Gerali A. and A. Locarno (2014), "Bounded rationality and de-anchoring of inflation expectations”, Banca d’Italia Occasional Papers, No. 252.

Draghi, M. (2014), “Unemployment in the euro area”, speech at the Economic Policy Symposium, Federal Reserve Bank of Kansas City, Jackson Hole, August 22.

Fisher, I. (1933), “Debt-Deflation Theory of Great Depressions”, Econometrica, Vol. 1(4), pp. 33757.

Eggertsson G. and P. Krugman (2012), "Debt, Deleveraging, and the Liquidity Trap: A FisherMinsky-Koo Approach”, The Quarterly Journal of Economics, Vol. 127(3), pp. 1469-1513.

Neri S., and A. Notarpietro (2014), “Inflation, debt and the zero lower bound”, Banca d'Italia Occasional Papers, No. 242.

Praet P. (2015), interview with Süddeutsche Zeitung, January 31.

Woodford M. (2003), “Interest and Prices: Foundations of a Theory of Monetary Policy”, Princeton University Press. 